\title{
Moxibustion for the treatment of ankylosing spondylitis: a systematic review and meta-analysis
}

\author{
Jiaojiao Hu, Yingying Mao, Yi Zhang, Ding Ye, Chengping Wen, Zhijun Xie \\ School of Basic Medical Sciences, Zhejiang Chinese Medical University, Hangzhou 310053, China \\ Contributions: (I) Study conception and design: All authors; (II) Administrative support: Z Xie; (III) Study inclusion and exclusion: J Hu, Y Mao; (IV) \\ Collection and assembly of data: J Hu, Y Mao, D Ye; (V) Data analysis and interpretation: J Hu, Y Mao, C Wen; (VI) Manuscript writing: All authors; \\ (VII) Final approval of manuscript: All authors. \\ Correspondence to: Zhijun Xie, PhD. TCM Clinical Basis Institute, School of Basic Medical Sciences, Zhejiang Chinese Medical University, 548 \\ Binwen Road, Hangzhou 310053, China. Email: xzj575@163.com.
}

Background: To systematically evaluate the efficacy of moxibustion in the treatment of ankylosing spondylitis (AS).

Methods: Seven electronic databases were systematically searched for relevant studies for inclusion from databases inception to December 31, 2018. Randomized controlled trials investigating the efficacy of moxibustion for AS treatment versus Western medicine $(\mathrm{Wm})$ treatment were included for systematic review and meta-analysis. Effect estimates were pooled using the fixed or random-effects models. Between-study heterogeneity and publication bias were also assessed. Stratification analyses were further performed based on the treatment plan of experimental groups.

Results: Twenty-six studies were eligible for inclusion with a total of 1,944 AS patients. Meta-analysis showed that compared with those receiving $\mathrm{Wm}$ treatment alone, patients receiving moxibustion combined with $W \mathrm{~m}$ treatment or moxibustion alone had a higher clinical efficacy rate [odds ratio $(\mathrm{OR})=4.21,95 \%$ confidence interval (CI): 2.91 to $6.10, \mathrm{P}<0.001$ for moxibustion combined with $W m$ versus $W m$; OR $=2.43$, 95\% CI: 1.62 to $3.65, \mathrm{P}<0.001$ for moxibustion alone versus $\mathrm{Wm}$ ]. In addition, patients receiving moxibustion combined with $\mathrm{Wm}$ treatment had lower levels of C-reactive protein [weighed-median difference $(\mathrm{WMD})=-6.33,95 \% \mathrm{CI}:-9.64$ to $-3.01, \mathrm{P}<0.001]$ and erythrocyte sedimentation rate (WMD $=-7.86,95 \%$ CI: -11.26 to $-4.46, \mathrm{P}<0.001)$ after treatment, respectively. Furthermore, moxibustion could also improve Schober test scores (WMD $=0.85,95 \% \mathrm{CI}: 0.15$ to $1.55, \mathrm{P}=0.017$ ), occipital-wall distances (WMD $=-0.55,95 \% \mathrm{CI}:-0.92$ to $-0.19, \mathrm{P}=0.003)$, and finger-ground distances $(\mathrm{WMD}=-3.64,95 \% \mathrm{CI}$ : -5.61 to $-1.68, \mathrm{P}<0.001)$ of AS patients.

Conclusions: This study suggests that moxibustion is an effective complementary treatment for AS patients. However, further large-scale multicenter clinical trials are needed to confirm these findings.

Keywords: Ankylosing spondylitis (AS); moxibustion; meta-analysis; randomized controlled trial; systematic review

Submitted Aug 16, 2019. Accepted for publication Jan 03, 2020.

doi: 10.21037/apm.2020.02.31

View this article at: http://dx.doi.org/10.21037/apm.2020.02.31

\section{Introduction}

Ankylosing spondylitis (AS) is a chronic autoimmune inflammatory disorder with joint damage primarily to the joints of spine and the sacroiliac, leading to progressive bone fusion of the spine (1). Nonsteroidal anti-inflammatory agents (NSAIDs), disease modifying antirheumatic drugs (DMARDs), glucocorticoid as well as biologic drugs are recommended as the principle treatments for AS patients (2). However, prolonged therapies with drugs such as NSAIDs 
may have potential cardiovascular, gastrointestinal and renal risks (3). Therefore, substitution and complementary therapies have been actively searched to improve the treatment strategy for AS patients.

Moxibustion is one of the complementary and alternative therapies frequently used by patients with rheumatic diseases worldwide, especially in East Asian countries such as China. It is a form of heat therapy in which dried plant materials called "moxa" are burned on or near the surface of the skin. Several systematic review and meta-analyses have shown that moxibustion is effective in relieving rheumatic diseases such as rheumatoid arthritis and knee osteoarthritis $(4,5)$. To date, there has been no critically designed systematic review assessing the efficacy and safety of moxibustion for the treatment of AS. A meta-analysis published in 2011 evaluated the effectiveness of moxibustion for major rheumatic conditions, however, only three trials related with AS were included (6). Therefore, in the present study, we performed a systematic review and meta-analysis of randomized controlled trials (RCTs) to assess the efficacy of moxibustion in the treatment of AS patients.

\section{Methods}

\section{Data source and search strategy}

This systematic review and meta-analysis were conducted adhering to the Preferred Reporting Items for Systematic Reviews and Meta-analysis (PRISMA) Statement. The protocol of the present study was registered and approved by PROSPERO under the registration number of CRD42019104815. Briefly, seven databases including PubMed, Cochrane Library, EMBASE, China National Knowledge Infrastructure (CNKI), Wanfang, VIP Database for Chinese Technical Periodicals and China Biology Medicine (CBM) were systematically searched from databases inception through December 31, 2018. No restrictions were applied on language, year of publication or publication status. References of related articles were manually searched for potential eligible studies for inclusion.

\section{Inclusion and exclusion criteria}

Studies were considered eligible for inclusion based on the following criteria: (I) randomized controlled trials; (II) participants are those diagnosed with AS; (III) studies comparing moxibustion alone or moxibustion combined with Western medicine $(\mathrm{Wm})$ to $\mathrm{Wm}$ alone for the treatment of AS patients. The exclusion criteria were: (I) observational or retrospective studies; (II) duplicated studies; (III) the control group was not treated with $\mathrm{Wm}$ alone; (IV) the experimental group used additional treatments (such as acupuncture, herbal therapy or rehabilitation).

\section{Data extraction}

Eligible studies were selected for detailed analysis and data extraction, which were performed by two investigators (JJ $\mathrm{Hu}$ and YY Mao). Disagreements were resolved through consensus. The following data were extracted from each study, which included first author, publication year, sample size, patient demographics, intervention measures in the experimental and control groups, outcome measurements and adverse events documented.

\section{Assessment of risk of bias}

We evaluated the quality of each study by using the Cochrane Risk of Bias tool (7), which consists of the following six items: (I) was the allocation sequence adequately generated? (II) was the allocation adequately concealed? (III) was knowledge of the allocated intervention(s) adequately presented during the study? (IV) were incomplete outcome data adequately addressed? (V) are reports of the study free of any suggestion of selective outcome reporting? (VI) was the study apparently free of other problems that could place it at risk of bias? Each item was classified into high $(\mathrm{H})$, low $(\mathrm{L})$, or unclear $(\mathrm{U})$ risk of bias, respectively.

\section{Data analysis}

Statistical analyses were performed using Stata version 12.0 (Stata Corp LP, College Station, TX, USA). We used Cochrane's $\mathrm{Q}$ test and $\mathrm{I}^{2}$ statistics to assess the magnitude of heterogeneity between studies $(8,9)$. For dichotomous variables, odds ratios (OR) and $95 \%$ confidence intervals (CIs) were used, while for continuous variables, weighedmedian difference (WMD) and 95\% CIs were used. These effect estimates were combined using fixed-effects $\left(\mathrm{I}^{2}<50 \%\right)$ or random-effects models $\left(\mathrm{I}^{2} \geq 50 \%\right)(10)$. Funnel plot was generated and publication bias was assessed using Egger's test. The trim-and-fill computation was used to estimate the effect of publication bias on the interpretation of the results when publication bias existed. Stratification analyses 
were further performed based on the treatment plan of experimental groups. P values of $<0.05$ were considered statistically significant.

\section{Results}

\section{Study selection and participants characteristics}

A flow chart of study inclusion and exclusion is shown in Figure S1. The initial screening yielded 1,176 articles, among which 26 studies (with data for 1,944 participants) were finally included. The included studies were published between 2002 and 2018 and originated in China. The median trial duration was 8 weeks. The sample size of included trials ranged from 24 to 220 participants. All the included trials used pure $\mathrm{Wm}$ as the control group. Eight trials used pure moxibustion in the experimental group (11-18), while 18 trials used moxibustion combined with Wm (19-36). The detailed information of the included studies is summarized in Table 1.

\section{Risk of bias assessment}

Twelve of the included trials reported appropriate sequence generation methods for the randomization process, while 14 trials were described as 'randomized'. None reported blinding because the blinding of participants and personnel was impossible to carry out in these studies. Almost every trial had high risk of bias according to the Cochrane risk of bias criteria (Table S1).

\section{Clinical efficacy}

The efficacy rate of the experimental group was 3.32 times of the pure $\mathrm{Wm}$ group (OR $=3.32,95 \% \mathrm{CI}: 2.53$ to $4.36, \mathrm{P}<0.001)$ with no statistically significant betweenstudy heterogeneity observed $\left(\mathrm{I}^{2}=0 \%\right)$. The funnel plot was symmetric and no publication bias was detected using Egger's test $(\mathrm{P}=0.337)$. Stratification analysis showed that the efficacy rate was higher in the subgroup of moxibustion combined with $\mathrm{Wm}$ versus $\mathrm{Wm}$ alone $(\mathrm{OR}=4.21,95 \% \mathrm{CI}$ : 2.91 to $6.10, \mathrm{P}<0.001)$ than in the subgroup of moxibustion alone versus $\mathrm{Wm}$ treatment alone ( $\mathrm{OR}=2.43,95 \% \mathrm{CI}$ : 1.62 to $3.65, \mathrm{P}<0.001)$ (Figure 1).

\section{Axis functions}

Compared with those receiving $\mathrm{Wm}$ treatment alone, the experimental group using moxibustion combined with $\mathrm{Wm}$ had better improvements in Schober test (WMD $=0.85$; 95\% CI: 0.15 to $1.55 ; \mathrm{P}=0.017$ ) (Figure $2 A$ ), occipital-wall distance (WMD $=-0.55 ; 95 \%$ CI: -0.92 to $-0.19 ; \mathrm{P}=0.003$ ) (Figure $2 B$ ), and finger-ground distance $(\mathrm{WMD}=-3.64$; 95\% CI: -5.61 to -1.68 ; $\mathrm{P}<0.001$ ) (Figure 2 C). However, no statistically significant improvements in chest expansion distance were observed between the two groups (WMD $=-0.04 ; 95 \%$ CI: -0.29 to $0.21 ; \mathrm{P}=0.733$ ) (Figure $2 D$ ).

\section{Inflammatory responses}

Compared with the control group, the experimental group treated with moxibustion combined with $\mathrm{Wm}$ had lower levels of C-reactive protein (CRP) (WMD $=-6.33,95 \%$ CI: -9.64 to $-3.01, \mathrm{P}<0.001$ ) (Figure $3 A$ ) and erythrocyte sedimentation rate (ESR) (WMD $=-7.86,95 \% \mathrm{CI}:-11.26$ to $-4.46, \mathrm{P}<0.001$ ) (Figure 3 B) after treatment, respectively. However, both CRP (WMD $=7.73,95 \%$ CI: -8.30 to 23.77, $\mathrm{P}=0.344$ ) (Figure $3 A$ ) and ESR levels (WMD =3.79, 95\% CI: -2.81 to $10.39, \mathrm{P}=0.261$ ) (Figure $3 B$ ) did not differ significantly between the experimental group treated with moxibustion alone and the control group using $\mathrm{Wm}$ alone.

\section{Adverse events}

Ten trials reported adverse events during treatment. In the control groups, the most commonly recorded adverse events were nausea, anorexia, diarrhea and hepatic injury, while in the experimental groups, burn injury was the most commonly seen adverse event. Overall, the experimental groups had fewer adverse effects reported compared with the control groups $(\mathrm{OR}=0.33 ; 95 \% \mathrm{CI}$ : 0.19 to 0.57 ; $\mathrm{P}<0.001$ ) (Figure 4).

\section{Discussion}

The current systematic review and meta-analysis showed that AS patients treated with moxibustion had better improvements in axis functions and inflammatory responses but fewer adverse effects compared with the control groups treated with $\mathrm{Wm}$ alone, suggesting that moxibustion might be a useful complementary and alternative therapy for AS patients.

Our analysis suggested that moxibustion could improve spinal mobility and inflammatory responses, which was in line with current evidence showing the anti-inflammatory effects of moxibustion. An in vivo study using collage- 


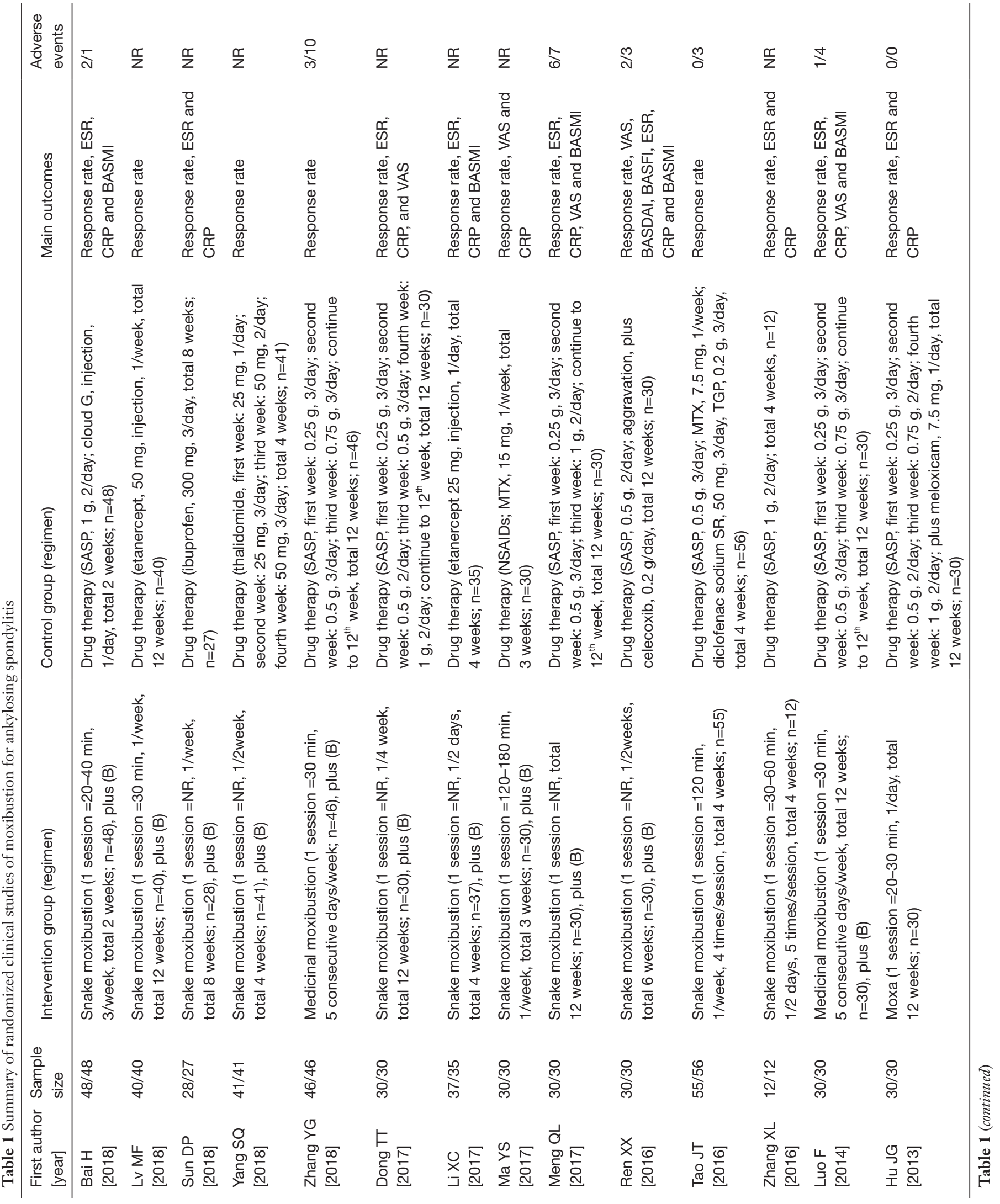




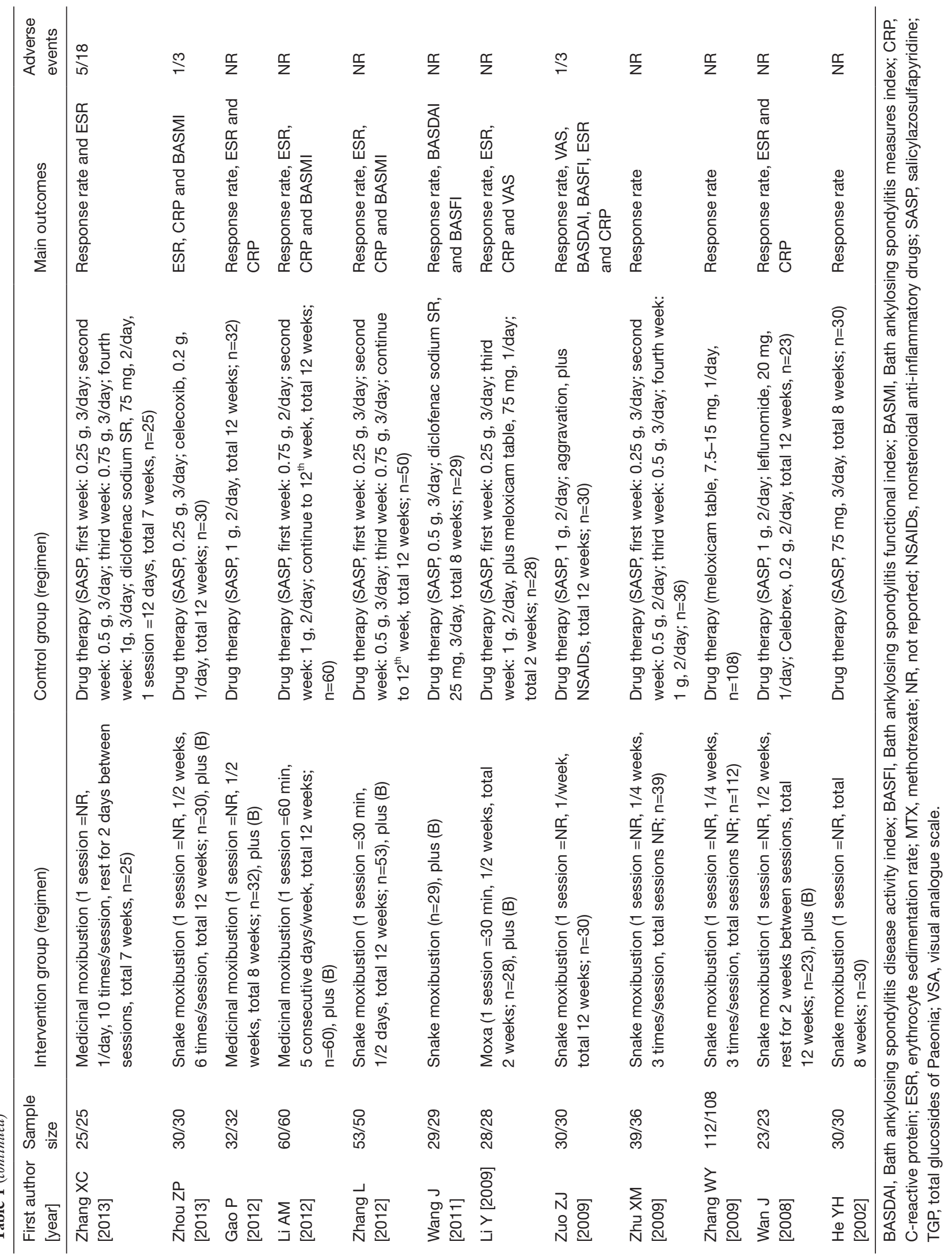




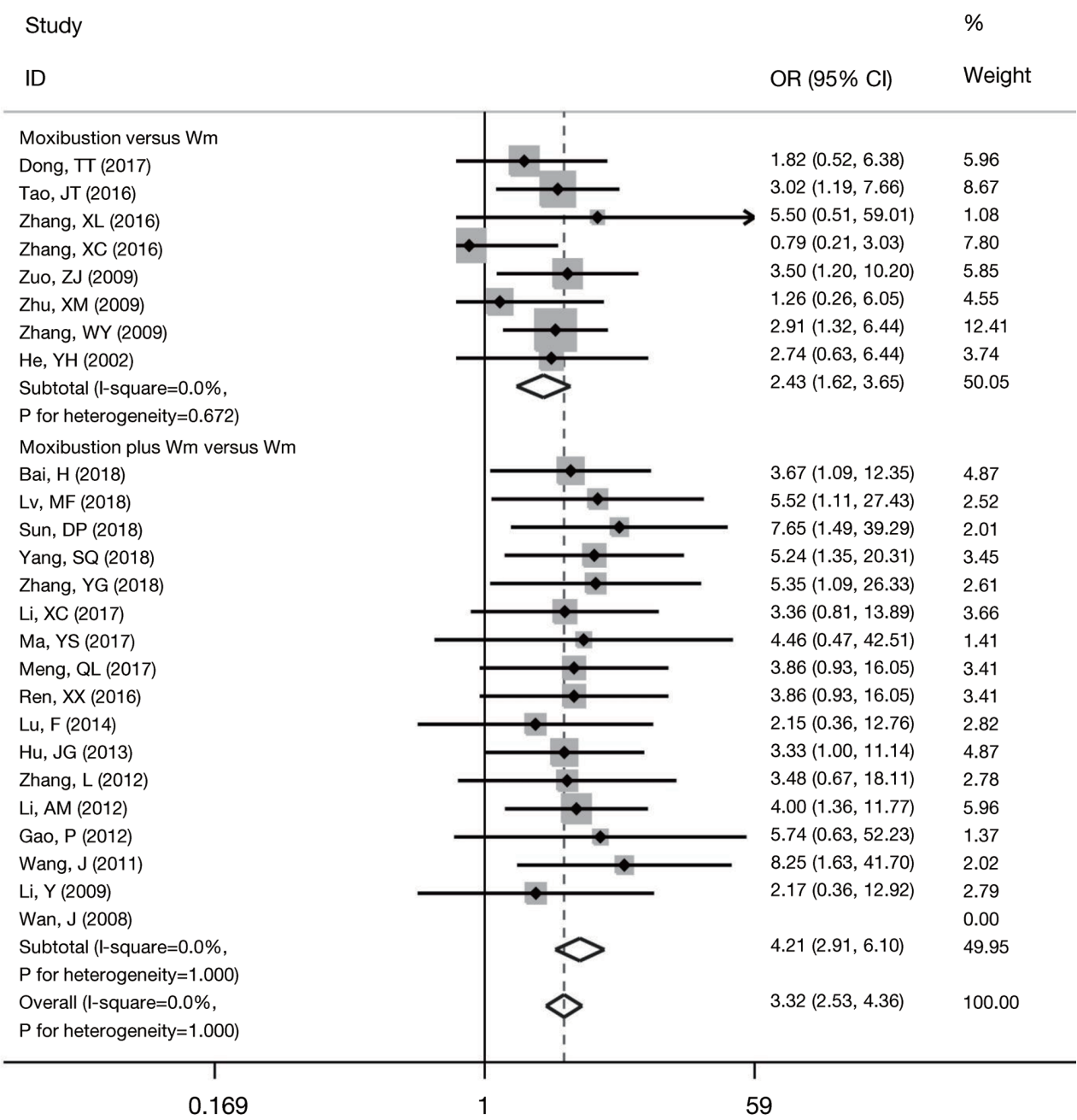

Figure 1 Forest plot of the clinical efficacy of moxibustion versus western medicine alone in the treatment of patients with ankylosing spondylitis.

induced arthritis (CIA) mouse model reported that the serum levels of interleukin (IL)-6 were significantly lower in the moxibustion treated group compared with untreated controls (37). The anti-inflammatory effect of moxibustion might be also related with the regulation of Treg cell number in spleen and the altered expression of Foxp 3 and NF- $\mathrm{NB}$ (38). As enthesis-associated changes are the primary lesions in AS, and inflammation at axial skeleton and sacroiliac may ultimately leads to restriction of spinal function (39); however, the widely used DMARDs of methotrexate (MTX) and salicylazosulfapyridine (SASP) have been reported to be beneficial effect to peripheral joints but have little effect on axial joints (40). Therefore, our findings clearly lend support to the use of moxibustion in the clinical management of patients with AS.
The merits and limitations to our study are worth mentioning. To the best of our knowledge, this is the first meta-analysis to evaluate the efficacy of moxibustion in the treatment of patients with AS. Furthermore, our study included a total 26 studies with a relatively large number of AS patients. The major limitation of the current study was that the quality of the included studies was relatively low, with high risk of bias according to the Cochrane Risk of Bias tool. Only twelve trials reported the random sequence generation methods. None employed patient blinding and accessor blinding due to the particularity of moxibustion treatment. In addition, though no statistically significant between-study heterogeneity was observed for the primary endpoint "clinical efficacy", we observed marked heterogeneity for the secondary endpoints such as 
A Study

ID
$\%$

WMD $(95 \% \mathrm{Cl}) \quad$ Weight

Moxibustion Plus Wm vs. Wm

Bai, H (2018)

Li, XC (2017)

Ren, XX (2016)

Lu, F (2014)

Subtotal (I-square $=92.9 \%$,

$P$ for heterogeneity $<0.001$ )

Overall (I-square $=92.9 \%$,

$P$ for heterogeneity $<0.001$ )

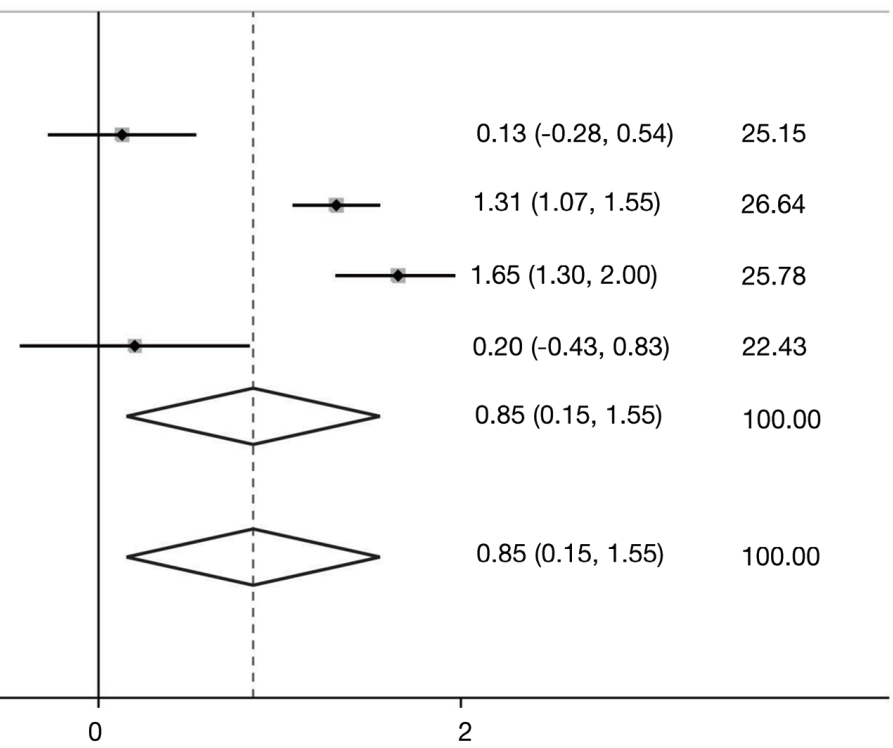

B Study

ID

Weight

Weight

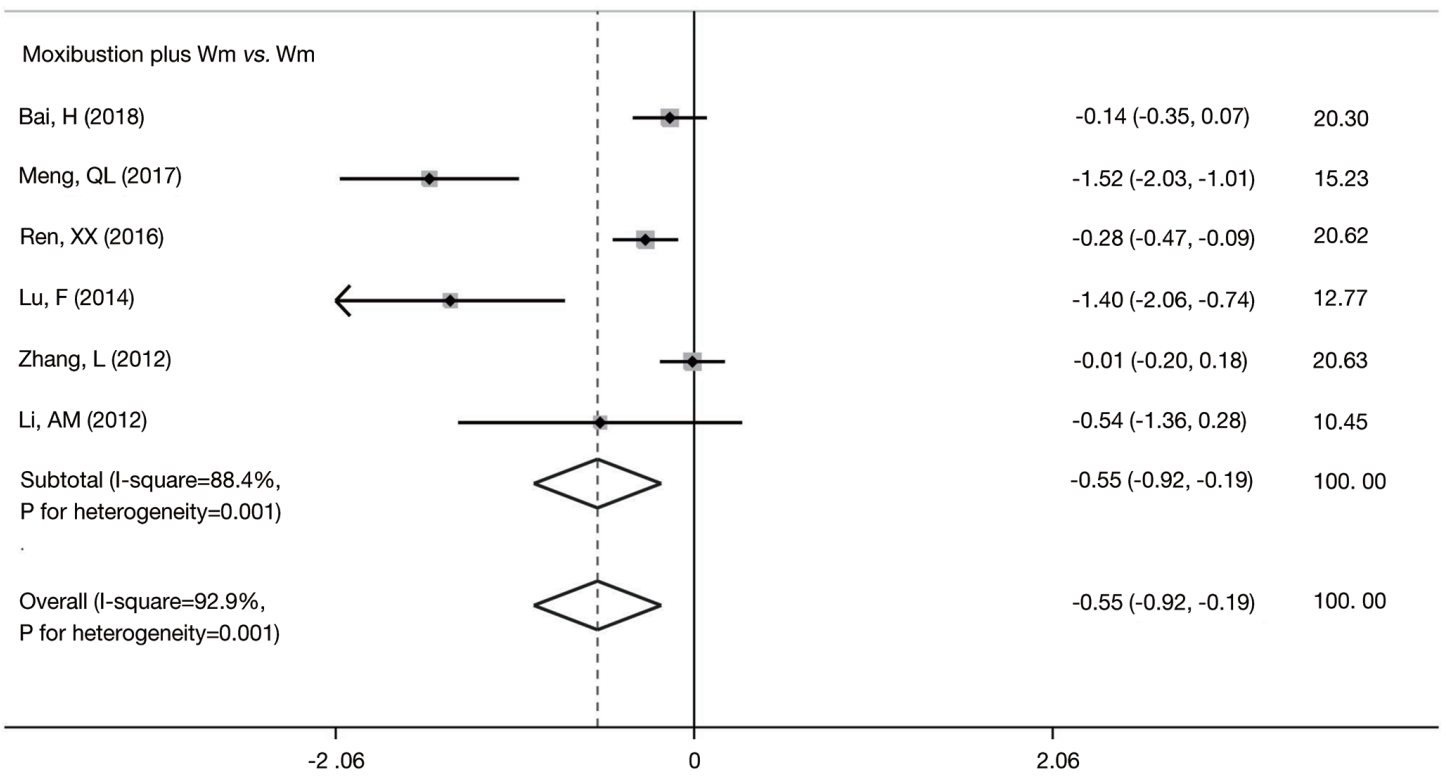




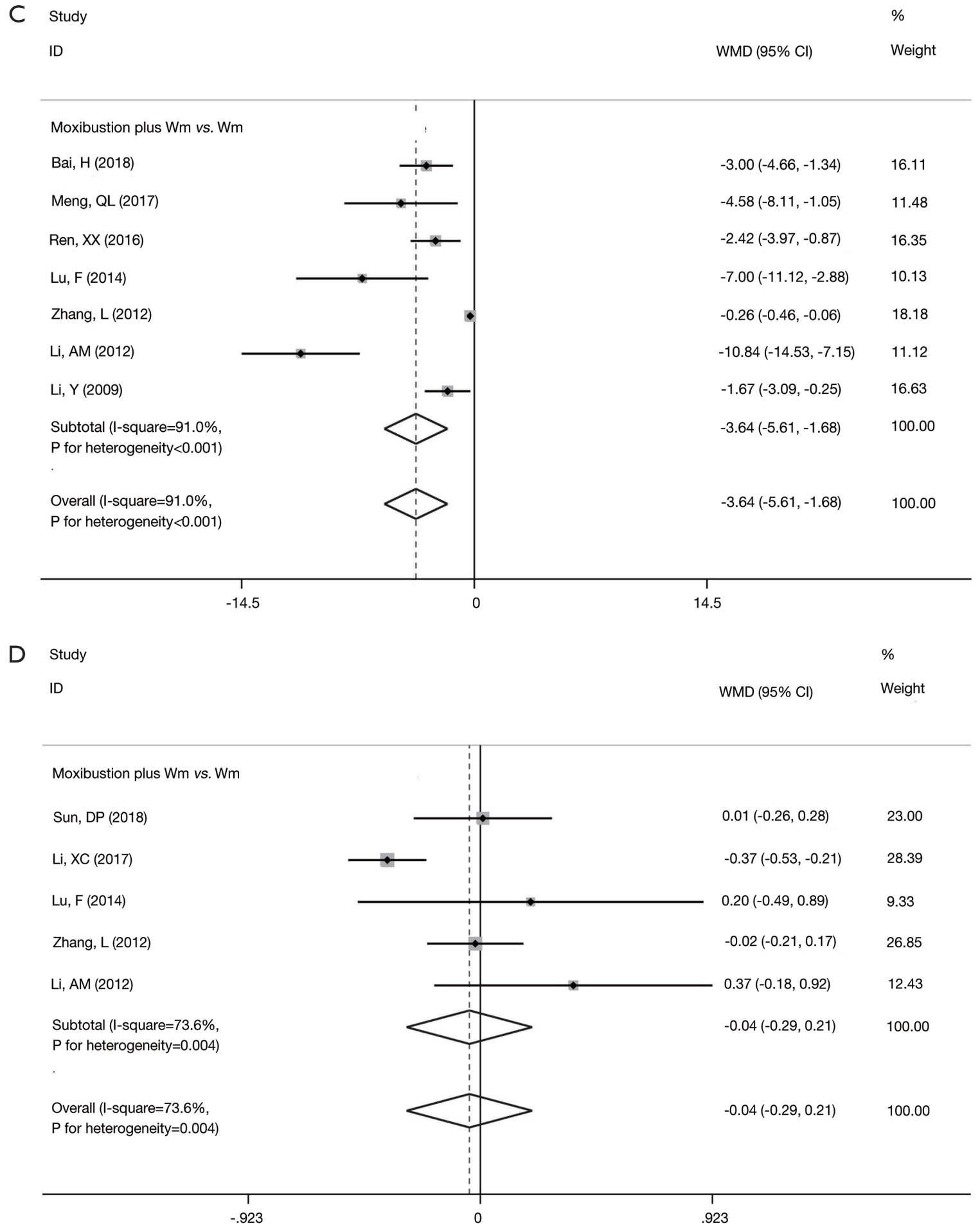

Figure 2 Forest plots of Schober test, occipital-wall distance, finger ground distance and chest expansion in patients with ankylosing spondylitis treated with moxibustion combined with western medicine versus western medicine treatment alone. (A) Schober test; (B) occipital-wall distance; (C) finger-ground distance; and (D) chest expansion. 


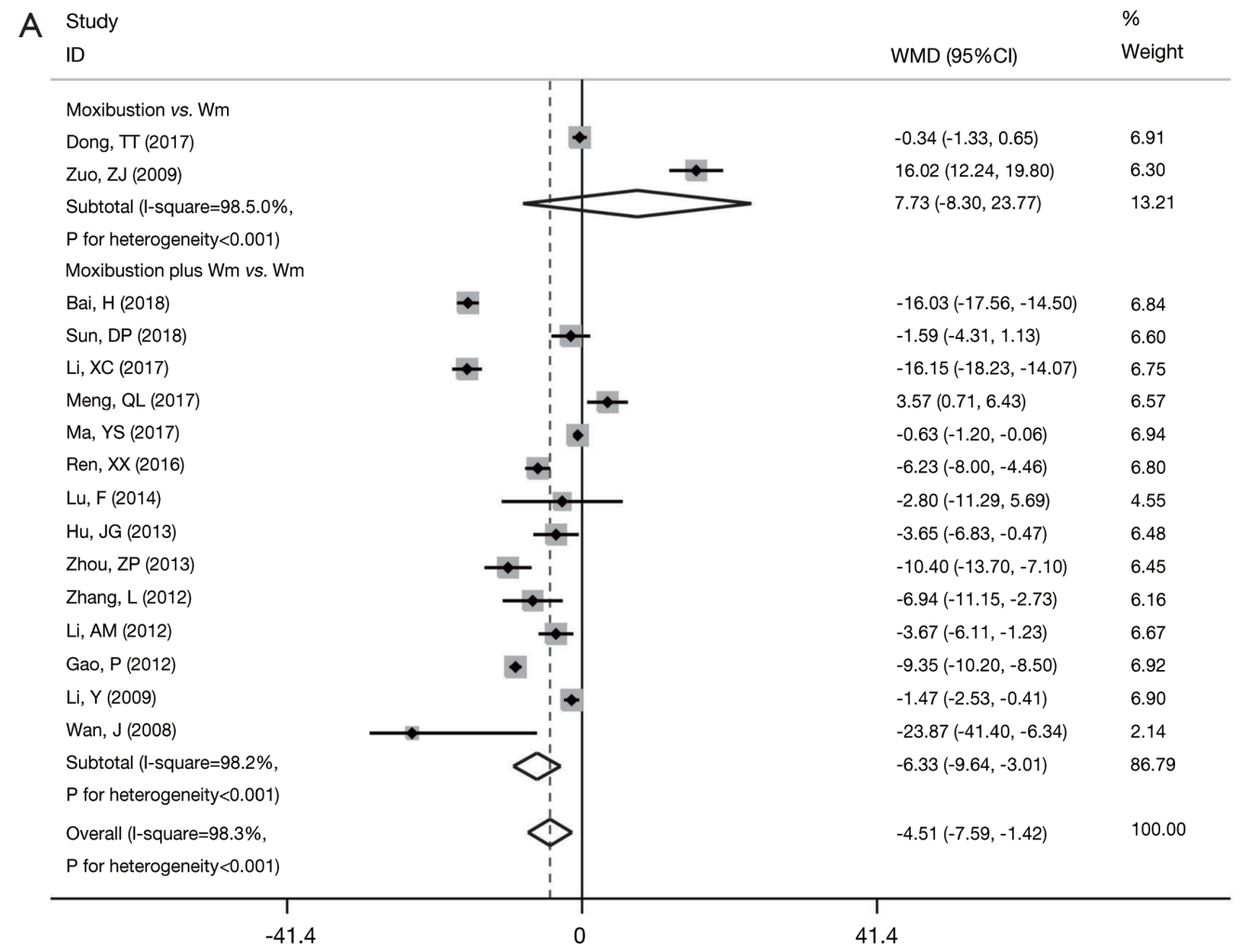

B Study

$\%$

ID

WMD $(95 \% \mathrm{Cl})$

Weight

Moxibustion vs. Wm Dong, TT (2017)

Zhang, XC (2013)

Zuo, ZJ (2009)

Subtotal (I-square $=94.8 .0 \%$,

$\mathrm{P}$ for heterogeneity<0.001)

Moxibustion plus Wm vs. Wm

Bai, $\mathrm{H}(2018)$

Sun, DP (2018)

$\mathrm{Li}, \mathrm{XC}(2017)$

Meng, QL (2017)

Ren, XX (2016))

Lu, F (2014)

$\mathrm{Hu}, \mathrm{JG}(2013)$

Zhou, ZP (2013)

Zhang, L (2012)

Li, AM (2012)

Gao, P (2012)

$\mathrm{Li}, \mathrm{Y}(2009)$

Wan, J (2008)

Subtotal (I-square $=92.1 \%$,

$\mathrm{P}$ for heterogeneity $<0.001$ )

Overall (I-square $=96.5 \%$,

$P$ for heterogeneity $<0.001$ )

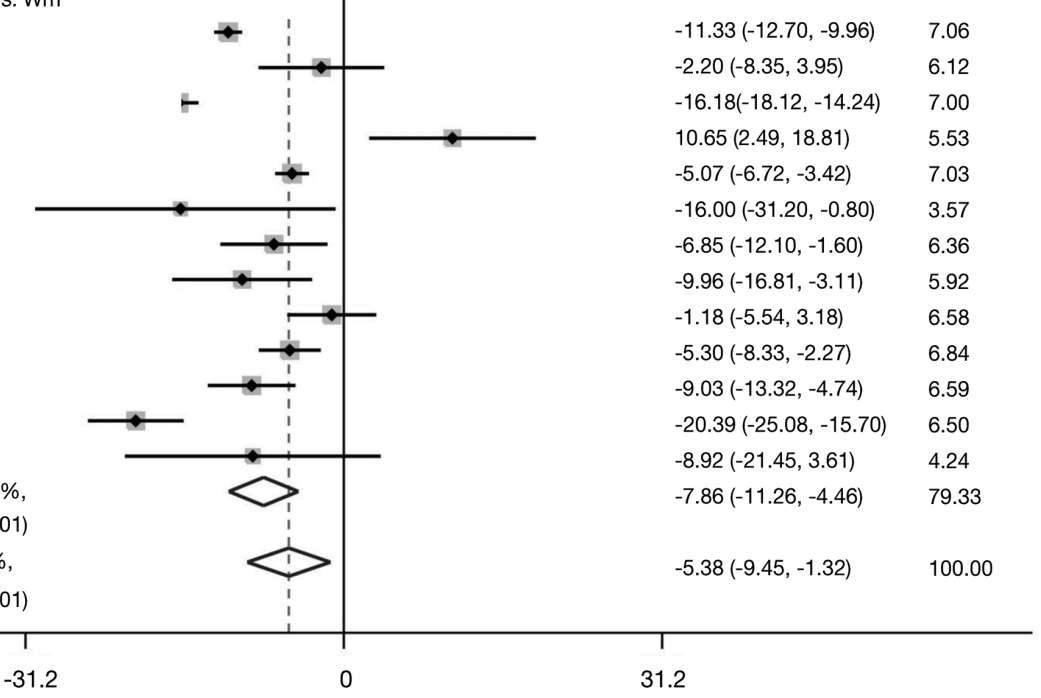

Figure 3 Forest plots of C-reactive protein and erythrocyte sedimentation rate in patients with ankylosing spondylitis treated with moxibustion combined with western medicine versus western medicine treatment alone. (A) C-reactive protein; and (B) erythrocyte sedimentation rate. 


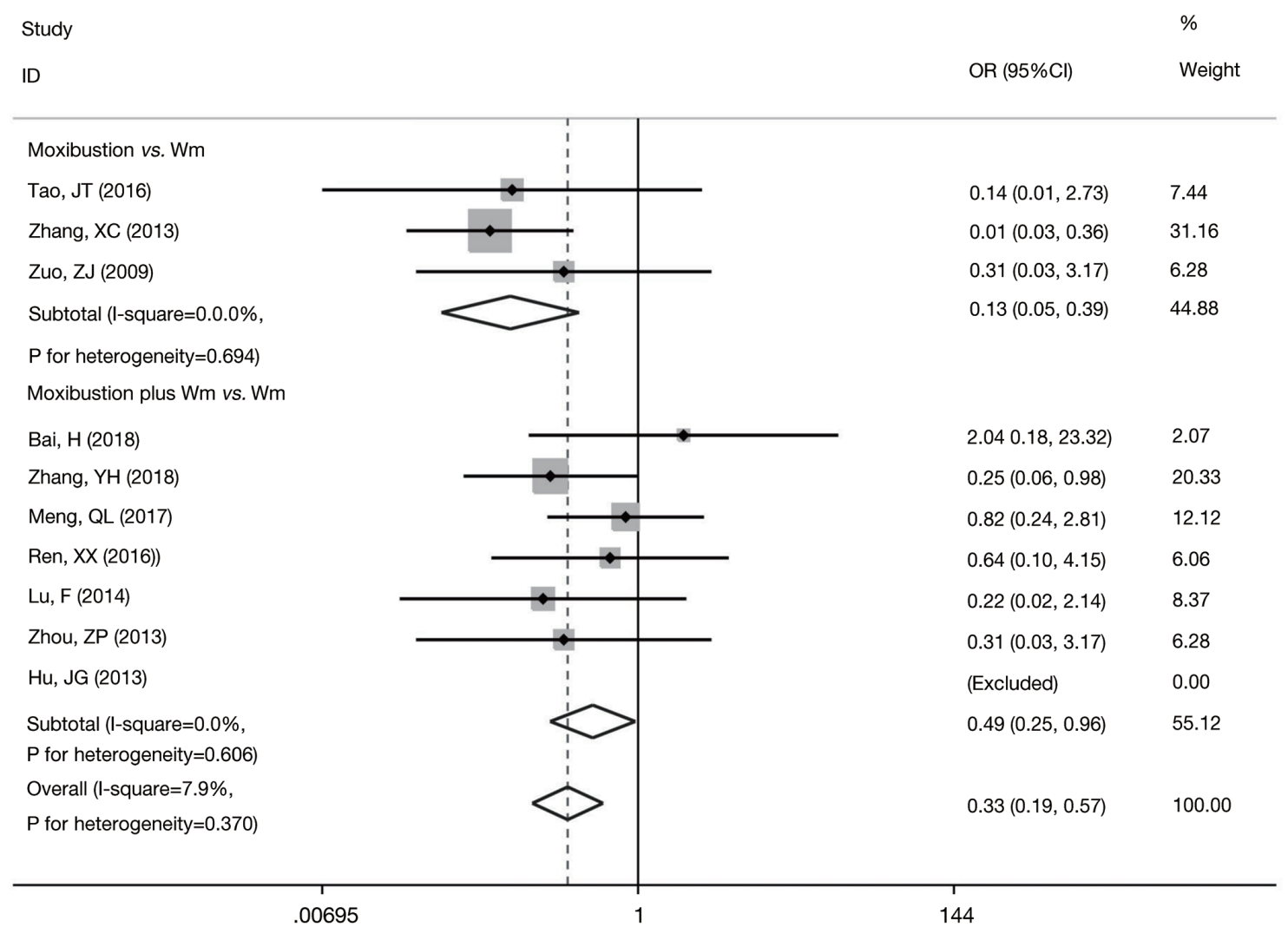

Figure 4 Forest plot of adverse events in patients with ankylosing spondylitis treated with moxibustion versus western medicine.

CRP, ESR and markers for axis functions. We performed stratification analyses as well as meta-regression, however, we did not detect contributing factors. The heterogeneity may be possibly related with the performances of the doctors, the quality of moxa made by Ay Tsao and others factor difficult to be controlled for in the trials. Furthermore, as treatment duration of the included studies were from 2 to 12 weeks, with a median duration of 8 weeks, the long-term efficacy of moxibustion in the treatment of AS remained to be further explored. In the future, largescale multicenter RCTs with better design are warranted to validate the findings of the current study.

\section{Conclusions}

Our study suggested that moxibustion was an effective complementary treatment for AS patients, especially in terms of improving spinal mobility and inflammatory responses. However, further large-scale trials with better design are needed to confirm these findings.

\section{Acknowledgments}

We greatly appreciate Mr. David J. H. Wu at the University of Minnesota Medical School for his help with the language of this manuscript.

Funding: This work was supported by the National Natural Science Foundation of China (81973663, 81873266 and 81803973), the Talent project of Zhejiang Association for Science and Technology (2018YCGC003), and the Zhejiang Province Medical and Health Science and Technology project (2015KYB260).

\section{Footnote}

Conflicts of Interest: All authors have completed the ICMJE uniform disclosure form (available at http://dx.doi. org/10.21037/apm.2020.02.31). The authors have no conflicts of interest to declare.

Ethical Statement: The authors are accountable for all 
aspects of the work in ensuring that questions related to the accuracy or integrity of any part of the work are appropriately investigated and resolved. The protocol of the present study was registered and approved by PROSPERO under the registration number of CRD42019104815.

Open Access Statement: This is an Open Access article distributed in accordance with the Creative Commons Attribution-NonCommercial-NoDerivs 4.0 International License (CC BY-NC-ND 4.0), which permits the noncommercial replication and distribution of the article with the strict proviso that no changes or edits are made and the original work is properly cited (including links to both the formal publication through the relevant DOI and the license). See: https://creativecommons.org/licenses/by-nc-nd/4.0/.

\section{References}

1. Braun J, Sieper J. Ankylosing spondylitis. Lancet 2007;369:1379-90.

2. Braun J, van den Berg R, Baraliakos X, et al. 2010 update of the ASAS/EULAR recommendations for the management of ankylosing spondylitis. Ann Rheum Dis 2011;70:896-904.

3. Bahadur S, Keshri L, Pathak K. Adverse drug reactions and safety considerations of NSAIDs: clinical analysis. Curr Drug Saf 2011;6:310-7.

4. Sun ZL, Xu X, Du SZ, et al. Moxibustion for treating rheumatoid arthritis: A systematic review and metaanalysis of randomized controlled trials. Eur J Integr Med 2014;6:621-30.

5. Song GM, Tian X, Jin YH, et al. Moxibustion is an Alternative in Treating Knee Osteoarthritis: The Evidence From Systematic Review and Meta-Analysis. Medicine 2016;95:e2790.

6. Choi TY, Kim TH, Kang JW, et al. Moxibustion for rheumatic conditions: A systematic review and metaanalysis. Clin Rheumatol 2011;30:937-45.

7. Higgins JSG. Cochrane handbook for systematic reviews of interventions. Cochrane Collaboration. Version 510 (Updated 2011).

8. Higgins JP, Thompson SG. Quantifying heterogeneity in a meta-analysis. Stat Med 2002;21:1539-58.

9. Higgins JP, Thompson SG, Deeks JJ, et al. Measuring inconsistency in meta-analyses. BMJ 2003;327:557-60.

10. DerSimonian R, Laird N. Meta-analysis in clinical trials. Control Clin Trials 1986;7:177-88.

11. Tao JT, Tong Y. The curative effect of moxibustion on ankylosing spondylitis. Contemporary Chin Med 2016;23:157-9.

12. Zhang XL, Mao ZN, Mao LY, et al. Clinical observation of 24 cases of ankylosing spondylitis treated by he's moxibustion therapy. Proceedings of the 2013 Acad Ann Conference of Gansu Acup Society 2016.

13. Hu JG, Chen XJ, Deng YX, et al. Clinical study on treatment of ankylosing spondylitis with moxibustion medicine. J Liaoning Med 2013;40:497-9.

14. Zhang XC. Therapeutic effect of "pain point" moxibustion on ankylosing spondylitis. Clin J Acup Moxi 2013;29:22-3.

15. Zuo ZJ, Ding Y, Guan XF, et al. Long snake moxibustion to treat ankylosing spondylitis. Chin Recovery 2009;24:400.

16. Zhu XM, Fen YH, Hu XW. Du moxibustion treatment of 39 cases of ankylosing spondylitis. J TCM 2009;50:625-6.

17. Zhang WY, Chen WG, Wang XC. Clinical observation of therapeutic effect of acupuncture powder on treatment of ankylosing spondylitis. Chin J TCM 2009;24:686-7.

18. He YH. The treatment of 30 cases of ankylosing spondylitis with cantharides powder. Shanghai J TCM 2002;(8):33.

19. Bai H. Clinical study on moxibustion treatment of ankylosing spondylitis. Henan J TCM 2018;38:111-4.

20. Lv MF, Hu XW, Geng LL, et al. Clinical observation on treatment of ankylosing spondylitis by long snake moxibustion. Guangming J Chin Med 2018;33:2086-8.

21. Sun DP. Clinical observation of 55 cases of ankylosing spondylitis treated with moxibustion combined with non-steroidal anti-inflammatory drugs. Chin Med J Metallurgical Industry 2018;35:69-70.

22. Yang SQ, Hou AP, Ren LL. A randomized, parallel controlled study of modified moxibustion combined with thalidomide (Sequential) in the treatment of ankylosing spondylitis (Shenxu Hanshi). J Pract Tradit Chin Intern Med 2018;32:15-7.

23. Zhang YG. Clinical observation on clinical efficacy of septum and moxibustion in treating kidney-deficiency and cold-induced ankylosing spondylitis. Modern Drug Use in China 2018;12:194-5.

24. Dong TT, Pang YZ, Li JJ, et al. Observation of curative effect of Moxibustion on Ankylosing Spondylitis to Improve Pain Symptoms and Its Effect on Thermal Graphics. Sichuan J TCM 2017;35:199-202.

25. Li XC, HX, Zhang J. Clinical observation of treatment of ankylosing spondylitis by moxibustion of snake combined with yisaipu. J Modern Chin Western Med 2017;26:1908-10. 
26. Ma YS. Clinical study of acupuncture on relieving back pain in patients with ankylosing spondylitis. J Chin Med 2017;32:1118-20.

27. Meng QL, Meng W'T, Zhan JP, et al. Treatment of early Shenxu Duhan ankylosing spondylitis with moxibustion combined with Western medicine: a report of 30 cases. TCM Res 2017;30:14-7.

28. Ren XX, Li BW. Clinical curative effect of moxibustion combined with ssalicylazosulfapyridine enteric-coated tablet in the treatment of kidney-deficiency and coldinduced ankylosing spondylitis. Modern Chin Doctors 2016;54:116-9.

29. Luo F. Clinical observation of mild-warm moxibustion treatment for ankylosing spondylitis with kidney deficiency du-cold type. Hubei Univ of Chin Med 2014.

30. Zhou ZP. Clinical study on improving spinal stiffness in ankylosing spondylitis. J Chin Med 2016;54:116-9.

31. Gao P, Xu N, Li AM. Clinical observation on the treatment of ankylosing spondylitis with intermittent moxibustion. Clin Study Chin Med 2012;4:60-1.

32. Li AM, Xu N, Gao P. Clinical observation of 60 cases of ankylosing spondylitis treated with intermittent moxibustion combined with salazylaminopyridine. J TCM 2012;53:219-21.

33. Zhang L, Wang ZL. Clinical study on treatment of ankylosing spondylitis by large moxibustion therapy. J

Cite this article as: Hu J, Mao Y, Zhang Y, Ye D, Wen C, Xie Z. Moxibustion for the treatment of ankylosing spondylitis: a systematic review and meta-analysis. Ann Palliat Med 2020;9(3):709-720. doi: 10.21037/apm.2020.02.31
TCM 2012;27:1065-6.

34. Wang J, Jiang Q, Zhu YW. Effect of moxibustion therapy on functional index of patients with ankylosing spondylitis. Shanghai J Acup 2011;30:395-6.

35. Li Y, Chen Y. Observation on the curative effect of moxibustion combined with drugs in treatment of ankylosing spondylitis. Collection of Rheumatism Papers of The Cross-strait Conference on the Development of TCM 2009.

36. Wan J, Li FQ. Clinical observation on treating 23 cases of ankylosing spondylitis with moxibustion. J Practi Chin Modern Med 2008:790.

37. Kogure M, Mimura N, Ikemoto H, et al. Moxibustion at mingmen reduces inflammation and decreases IL-6 in a collagen-induced arthritis mouse model. J Acupunct Meridian Stud 2012;5:29-33.

38. Liu Z, Li X, Zhao C, et al. Effects of moxibustion on Treg/ Th17 cell and its signal pathway in mice with rheumatoid arthritis. Zhongguo Zhen Jiu 2017;37:1083-91.

39. Taurog JD, Chhabra A, Colbert RA. Ankylosing Spondylitis and Axial Spondyloarthritis. N Engl J Med 2016;374:2563-74.

40. Haibel H, Brandt HC, Song IH, et al. No efficacy of subcutaneous methotrexate in active ankylosing spondylitis: a 16-week open-label trial. Ann Rheum Dis 2007;66:419-21. 
Supplementary

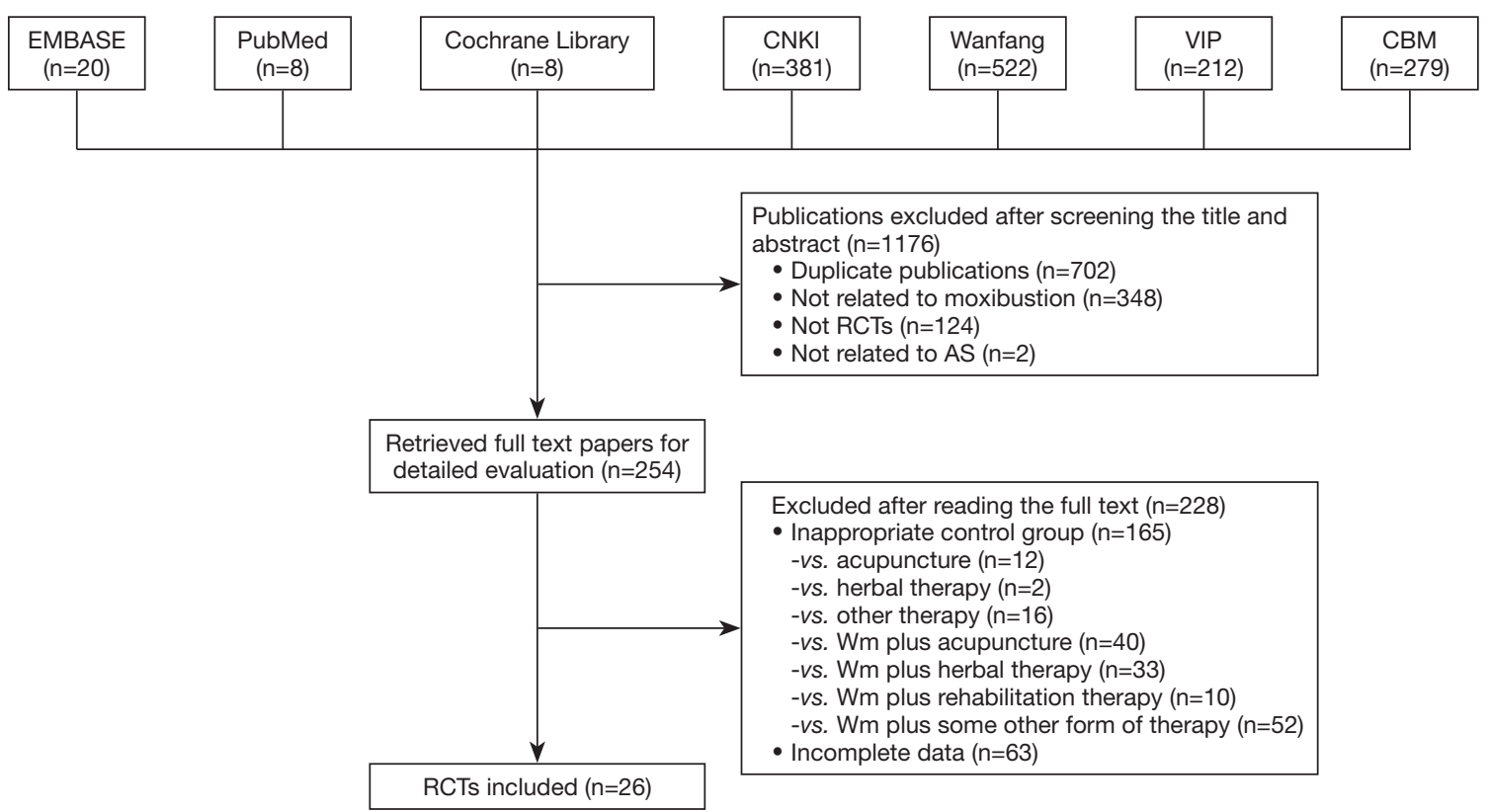

Figure S1 Flow diagram of study inclusion and exclusion. 
Table S1 Quality assessment of included randomized controlled trials

\begin{tabular}{|c|c|c|c|c|c|c|}
\hline First author [year] & $\begin{array}{l}\text { Random sequence } \\
\text { generation }\end{array}$ & $\begin{array}{l}\text { Allocation } \\
\text { concealment }\end{array}$ & $\begin{array}{l}\text { Blinding of participants } \\
\text { and personnel }\end{array}$ & $\begin{array}{l}\text { Blinding of } \\
\text { outcome data } \\
\text { assessment }\end{array}$ & $\begin{array}{l}\text { Incomplete } \\
\text { outcome data }\end{array}$ & $\begin{array}{l}\text { Selective } \\
\text { reporting }\end{array}$ \\
\hline Bai H [2018] & $\mathrm{H}$ & u & $\mathrm{H}$ & U & L & L \\
\hline Lv MF [2018] & $\mathrm{L}$ & u & $\mathrm{H}$ & u & L & L \\
\hline Sun DP [2018] & L & $u$ & $\mathrm{H}$ & u & L & L \\
\hline Yang SQ [2018] & $\mathrm{L}$ & u & $\mathrm{H}$ & u & $\mathrm{H}$ & $\mathrm{L}$ \\
\hline Zhang YG [2018] & $\mathrm{H}$ & u & $\mathrm{H}$ & u & L & L \\
\hline Dong TT [2017] & $\mathrm{H}$ & u & $\mathrm{H}$ & u & L & L \\
\hline Li XC [2017] & $\mathrm{H}$ & $u$ & $\mathrm{H}$ & u & L & L \\
\hline Ma YS [2017] & $\mathrm{H}$ & u & $\mathrm{H}$ & u & L & $\mathrm{L}$ \\
\hline Meng QL [2017] & $\mathrm{H}$ & u & $\mathrm{H}$ & u & L & L \\
\hline Ren XX [2016] & L & $u$ & $\mathrm{H}$ & $u$ & L & L \\
\hline Tao JT [2016] & L & $u$ & $\mathrm{H}$ & $u$ & L & L \\
\hline Zhang XL [2016] & L & u & $\mathrm{H}$ & $\mathrm{U}$ & L & L \\
\hline Luo F [2014] & $\mathrm{L}$ & u & $\mathrm{H}$ & u & $\mathrm{L}$ & $\mathrm{L}$ \\
\hline Hu JG [2013] & L & $u$ & $\mathrm{H}$ & U & L & L \\
\hline Zhang XC [2013] & $\mathrm{H}$ & $u$ & $\mathrm{H}$ & u & L & $\mathrm{L}$ \\
\hline Zhou ZP [2013] & L & u & $\mathrm{H}$ & u & L & $\mathrm{L}$ \\
\hline Gao P [2012] & $\mathrm{H}$ & $u$ & $\mathrm{H}$ & $u$ & L & L \\
\hline Li AM [2012] & L & $u$ & $\mathrm{H}$ & $u$ & L & L \\
\hline Zhang L [2012] & $\mathrm{H}$ & U & $\mathrm{H}$ & $u$ & L & L \\
\hline Wang J [2011] & $\mathrm{H}$ & $u$ & $\mathrm{H}$ & $u$ & L & L \\
\hline Li Y [2009] & $\mathrm{H}$ & u & $\mathrm{H}$ & u & L & $\mathrm{L}$ \\
\hline Zuo ZJ [2009] & L & $u$ & $\mathrm{H}$ & $u$ & L & L \\
\hline Zhu XM [2009] & L & L & $\mathrm{H}$ & U & L & L \\
\hline Zhang WY [2009] & $\mathrm{H}$ & u & $\mathrm{H}$ & u & L & L \\
\hline Wan J [2008] & $\mathrm{H}$ & U & $\mathrm{H}$ & u & L & L \\
\hline $\mathrm{He} \mathrm{YH}$ [2002] & $\mathrm{H}$ & U & $\mathrm{H}$ & u & $\mathrm{L}$ & L \\
\hline
\end{tabular}

Note: $\mathrm{H}, \mathrm{L}$, and $\mathrm{U}$ represents high risk, low risk, and unclear, respectively. 